\title{
Facial Motor Evoked Potential Techniques and Functional Prediction during Cerebello-pontine Angle Surgery
}

\author{
Jae-Seung Baek ${ }^{1}$, Sang-Ku Park ${ }^{1}$, Dong-Jun Kim ${ }^{1}$, Chan-Woo Park ${ }^{1}$, Sung-Hyuk Lim ${ }^{1}$, Jang Ho Lee²,
} Young-Kuk Cho ${ }^{3}$

${ }^{1}$ Department of Neurology, Samsung Medical Center, Seoul, Korea

${ }^{2}$ Department of Clinical Laboratory Science, Semyung University, Jecheon, Korea

${ }^{3}$ Department of Medical Laboratory Science, Seoyeong University, Gwangju, Korea

\section{소뇌교각 수술 중에 안면운동유발전위의 검사방법과 기능적 예측인자}

\author{
백재승 ${ }^{1}$, 박상구 $^{1}$, 김동준 $^{1}$, 박찬우 $^{1}$, 임성혁 $^{1}$, 이장호 $^{2}$, 조영국 $^{3}$ \\ ${ }^{1}$ 삼성서울병원 신경과, ${ }^{2}$ 세명대학교 임상병리학과, ${ }^{3}$ 서영대학교 임상병리과
}

Key words: Cerebellopontine angle, Facial nerve, Intraoperative monitoring, Motor evoked potential, Transcranial electrical stimulation

\footnotetext{
This is an Open Access article distributed under the terms of the Creative Commons Attribution Non-Commercial License (http://creativecommons.org/licenses/by-nc/4.0) which permits unrestricted non-commercial use, distribution, and reproduction in any medium, provided the original work is properly cited.
}

Copyright @ 2018 The Korean Society for Clinical Laboratory Science. All rights reserved.

\begin{abstract}
Facial motor evoked potential (FMEP) by multi-pulse transcranial electrical stimulation (mpTES) can complement free-running electromyography (EMG) and direct facial nerve stimulation to predict the functional integrity of the facial nerve during cerebello-pontine angle (CPA) tumor surgery. The purpose of this paper is to examine the standardized test methods and the usefulness of FMEP as a predictor of facial nerve function and to minimize the incidence of facial paralysis as an aftereffect of surgery. TES was delivered through electrode Mz (cathode) - M3/M4 (anode), and extracranially direct distal facial muscle excitation was excluded by the absence of single pulse response (SPR) and by longer onset latency (more than $10 \mathrm{~ms}$ ). FMEP from the orbicularis oris (o.oris) and the mentalis muscle simultaneously can improve the accuracy and success rate compared with FMEP from the o.oris alone. Using the methods described, we can effectively predict facial nerve outcomes immediately after surgery with a reduction of more than $50 \%$ of FMEP amplitude as a warning criterion. In conclusion, along with free-running EMG and direct facial nerve stimulation, FMEP is a useful method to reduce the incidence of facial paralysis as a sequela during CPA tumor surgery.
\end{abstract}

Corresponding author: Jae-Seung Baek Department of Neurology, Samsung Medical Center, 81 Irwon-ro, Gangnam-gu, Seoul 06351, Korea Tel: 82-2-3410-2737 Fax: 82-2-3410-2759 E-mail: jslove.back@samsung.com

Received: September 13, 2018 Revised $1^{\text {st: }}$ October 12, 2018 Revised 2 ${ }^{\text {nd }}$ : October 22, 2018 Accepted: October 22, 2018

\section{서 론}

수술 중 신경감시는 현대 신경외과 수술에서 사망률은 줄이 고 운동신경과 감각신경 그리고 뇌신경 기능 보존 등의 수술 결 과를 향상시킬 수 있는 방법 중 하나이다[1]. 그 중 자유 진행 근 전도(free-running EMG)와 직접적인 안면 신경 전기 자극법 (direct facial nerve electrical stimulation)의 도입은 소뇌교 각 종양 수술 중에 안면 신경 손상으로 발생하는 후유증인 안면 마비 발생률을 감소시켰다[2-5].

첫 번째 검사인 자유 진행 근전도는 안면 근육에 기록 전극을 부착하고 실시간으로 안면 신경이 자극될 때 발생하는 신경 긴 장성의 발산(neurotonic discharge) 즉, 근전도 반응을 보는 것 
이다. 이런 반응은 리트랙터(retractor)로 인한 신경 당김, 종양 절제 중에 근접한 신경 손상과 같은 의도 하지 않은 손상성 안면 신경이 자극될 때 발생하고 이 때 집도의에게 알린다. 그러나, 수술 중 식염수 세척, 지혈솜 압박 등의 안면 신경에 손상을 가하 지는 않지만 간접적인 자극도 생기기 때문에 근전도 반응이 많 이 있었다고 해서 꼭 안면 신경의 손상을 나타내지는 않는다[6]. 게다가 수술 초기 큰 종양으로 인해 안면 신경이 식별되기도 전 에 수술 가위, 메스, 바이폴라 포셉 등의 날카로운 도구에 0.7 $\mathrm{mm}$ 이하의 작은 안면 신경이 집도의도 모르게 순식간에 절단 되면 근전도 반응은 유발되지 않을 수 있기 때문에 그들의 부재 가 안면 신경의 기능적인 완전성(integrity)을 보장하지 못한다 $[3,7]$. 즉, 근전도 반응은 신경 손상 정도의 정확한 기능평가는 할 수 없는 단점이 있다. 하지만 이러한 단점에도 불구하고 수술 중 집도의에게 실시간으로 안면 신경의 자극 여부을 제공하는 목적만으로 근전도 반응검사를 시행해 오고 있다[3].

두 번째 검사인 직접적인 안면 신경 전기 자극에 반응하는 안 면 근육에서의 복합 근육 활동 전위(compound muscle action potentials, $\mathrm{CMAPS}$ )는 신경의 기능평가를 하는 검사로서 자유 진행 근전도를 보완한다. 소뇌교각 종양을 기준으로 안면신경 의 근위부인 근기시부(root exit zone) 및 원위부인 내이도 (internal auditory canal, IAC)에서 최대상(supramaximal)자 극에 대한 안면 근육의 복합 근육 활동 전위 비율이 $30 \%$ 이상일 때와, 근기시부 자극 임계치(threshold)가 $0.3 \mathrm{~mA}$ 보다 같거나 작을 때가 만족스러운 수술 후 안면 기능을 예측한다[2, 8, 9]. 그 러나 이 검사는 근기시부 안면신경이 식별된 후에 집도의가 수 술을 잠시 멈추고 단극성 신경 자극기(monopolar nerve stimulator) (Figure 1)로 직접 자극을 해야 하기 때문에 간헐적 으로 진행이 되고 수술 절차를 지연시킬 수 있다. 이러한 이유로 인하여 집도의들이 자주 시행하지 않는다[10]. 그리고 수술 중 에 안면 신경 식별이 매우 어려운 큰 종양의 경우는 뇌간의 해부 학적 변형과 대부분의 수술 중에 종양에 안면신경이 가려져있

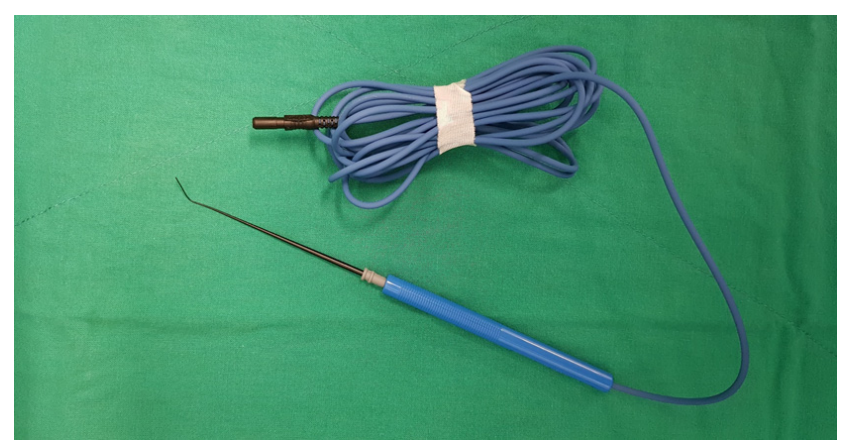

Figure 1. Monopolar stimulator.
어 직접적인 안면 신경 전기 자극 시행 가능성 여부가 집도의의 안면신경 근기시부 위치를 정확하게 알아내는 능력에 높게 의 존한다[5, 11, 12].

앞에서 언급한 자유 진행 근전도의 부정확한 안면 신경의 기 능 예측과 직접적인 안면 신경 전기 자극의 간헐적이고 큰 종양 수술일 경우에는 시행조차 못할 수 있는 단점들 때문에 여전히 안면 마비는 환자가 소뇌교각 종양수술을 받을 때 주로 걱정되 는 후유증이다[11, 13$]$.

그래서 이런 단점들을 보완한 근기시부 안면 신경을 직접 확 인 할 필요 없고 직접적인 안면 신경 전기 자극을 위해 수술을 중 간에 중단하지 않아도 되고 안면 신경을 집도의가 원할 때마다 검사할수있는다중펄스경두개전기자극(multi-pulse transcranial electrical stimulation, mpTES)에 의한 안면운동유발전위 (facial motor evoked potential, FMEP)가 도입이 되었다. 다 중펄스경두개전기자극에 의한 운동유발전위는 대뇌 운동피질 시스템의 평가를 위한 방법이다[14-16]. 안면 신경 감시를 위한 피질연수로(corticobulbar tract)로 이 기술을 적용하면 안면 신경의 기능을 예측할 수 있다[11, 18]. 그러나 이 검사는 자극 전극과 측정되는 안면 근육이 근접해 있어 자극이 강하면 피질 연수로뿐만 아니라 두개 외로 전파되어 직접적으로 말초안면근 육을 자극시켜 검사의 정확도가 떨어질 수 있다[18]. 그리고 자 극 잡파 혼입도 많아서 안면운동유발전위 결과 분석이 어려워 국내에서는 거의 시행되고 있지 않다. 본원에서도 수술 중에 자 유 진행 근전도와 직접적인 안면 신경 전기 자극법만으로 최근 까지 감시를 했었고 수술 중에 안면신경 손상 없이 끝났다고 생 각했지만 수술 직후 안면마비가 발생한 환자들이 발생하고 있 는 실정이다. 따라서 안면운동유발전위를 통하여 안면마비의 발생률의 유의미한 감소효과를 관찰해보고자 하였다.

본 논문에서는 소뇌교각 종양 수술 중에 다중펄스경두개전 기자극에 의한 안면운동유발전위의 직접적인 말초 안면 근육 자극없이 정확하게 검사하는 방법들과 수술 직후 안면 신경 결 과 예측인자로서의 유용성을 알아보고 수술 후 중대한 후유증 인 안면 마비의 발생률을 최소화하는 것을 목적으로 하였다.

\section{재료 및 방법}

\section{1. 검사장비}

수술장에서 사용하는 수술중 신경계추적감시(intraoperative neuro-monitoring, INM) 장비는 Xltek Protektor (Natus Medical Incor.)를 사용하였다. 안면운동유발전위를 위한 세팅 은 Range $\pm 1 \sim 10 \mathrm{mV}$, Reject Threshold $\pm 1 \sim 10 \mathrm{mV}$, 
LFF/HFF: 100 150 Hz/3 5 KHz, Timebase 5 ms/div, Amplitude $100 \mu \mathrm{V}$ 로 설정하여 검사를 하였다.

\section{2. 검사방법}

2018년 5월부터 2018년 7월까지 소뇌교각 종양환자 14명 을 대상으로 분석을 하였다. 나이는 평균 50 ( \pm 11.64$)$ 세였고, 여자 9명, 남자 5명이었다. 종양의 분류는 전정신경초종 (vestibular schwannoma)이 9명, 수막종(meningioma)이 3 명, 경정맥공 신경초종(jugular foramen schwannoma)이 1 명, 혈관 아세포종(hemangioblastoma)이 1명이였고 종양 크 기는 2 4.7 cm 이였다(Table 1). 환자들은 수술 전 의료진에게 수술 동의서를 작성하였으며, 수술 동의서에 따라 수술 중 유발 전위검사를 시행하였다. 자유 진행 근전도와 직접적인 안면신 경자극법을 이용해서 안면 신경의 위치를 탐색하고[20] 안면운 동유발전위를 이용해서 경막 절개 전(before dura open)을 기 준파형(baseline) 으로 해서 안면신경의 기능적인 완전성을 감 시하였다. 파형의 진폭이 $50 \%$ 이상 감소되면 즉시 집도의에게

Table 1. Patient demographics

\begin{tabular}{lc}
\hline SEX & \\
\hline Male & 5 \\
Female & 9 \\
Median age, y & 50 \\
Range & $23 \sim 64$ \\
\hline Diagnosis \\
\hline Vestibular schwannoma \\
Meningioma & 9 \\
Jugular foramen schwannoma & 3 \\
Hemangioblastoma & 1 \\
\hline
\end{tabular}

알리기로 하였다. 수술 종양제거 후 피부 봉합 때 파형(final)을 기준파형과 비교한 안면운동유발전위 비율을 측정하였다[18]. 안정적인 안면운동유발전위를 위해 자극법은 1 5 pulse, duration; $50 \mu \mathrm{sec}$, interstimulus interval; $1 \sim 2 \mathrm{~ms}$ 이고자극 전극은 음극(cathode)은 $\mathrm{Mz}$ ( $\mathrm{Cz}$ 전방으로 $1 \mathrm{~cm}$ ), 양극(anode) 은 수술 부위가 오른쪽일 경우에 $\mathrm{M} 3$, 왼쪽일 경우에 $\mathrm{M} 4$ (C3, $\mathrm{C} 4$ 전방으로 $1 \mathrm{~cm}$ )에 바늘전극으로 부착했다(전극 배치법: INTERNATIONAL 10 20 EEG SYSTEM) (Figure 2). 기록 전 극은 수술 동측 구륜근(orbicularis oris)과 턱근(mentalis)에 바 늘전극을 2 개씩 부착했다. 저체온이나 저혈압 등의 전신적인 원 인, 기술적인 에러, 마취심도에 따른 영향과 안면 신경의 손상을 구별하기 위한 대조군으로 수술 동측의 단무지외전근

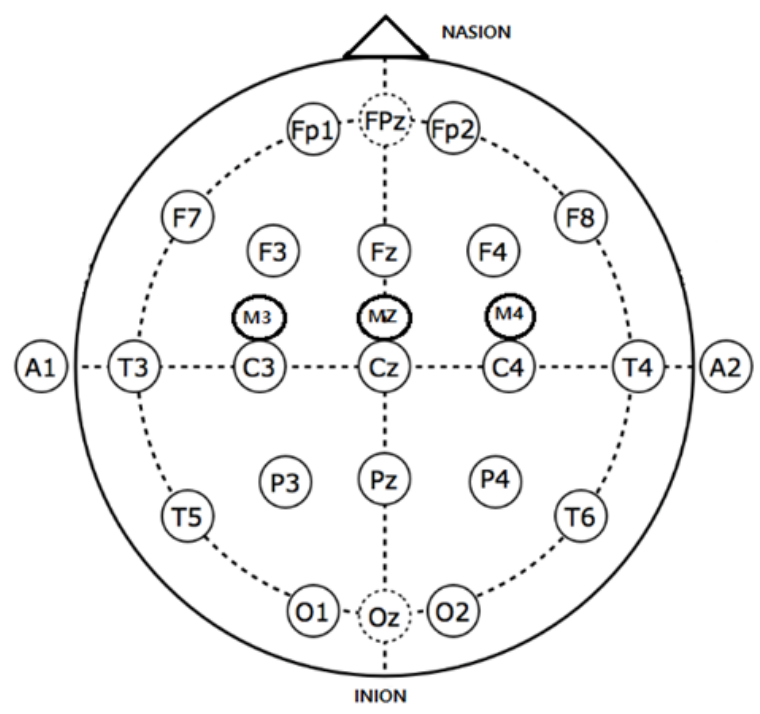

Figure 2. Electrode placement.
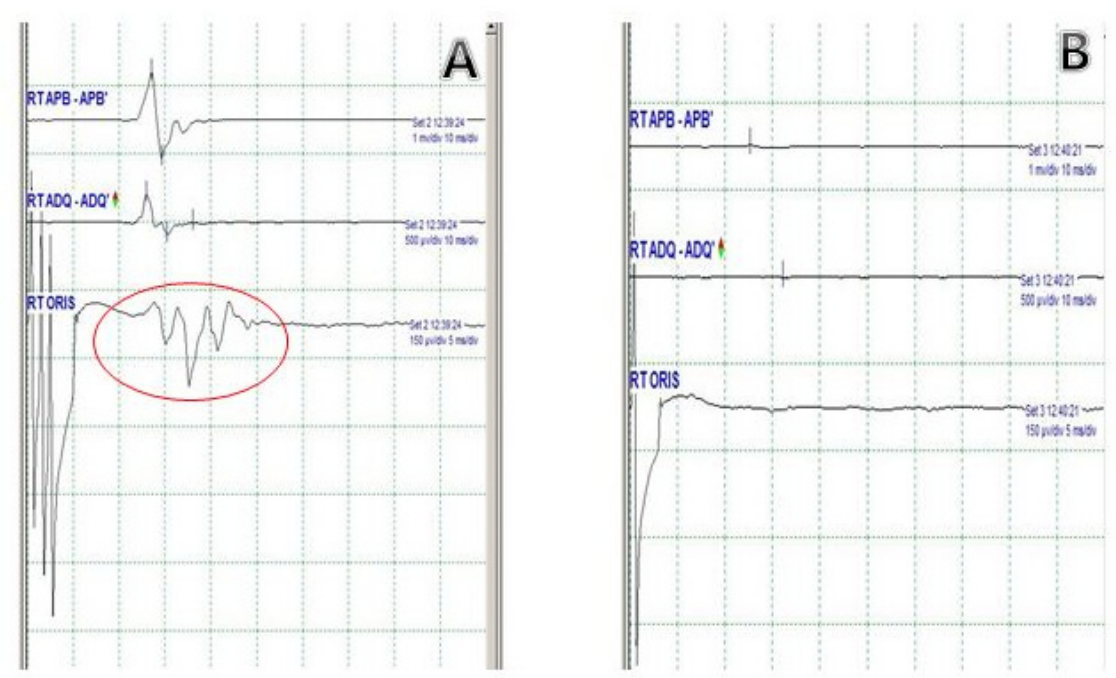

Figure 3. Single pulse response of the facial MEP recorded from the right orbicularis oris (o. oris) muscle. The facial MEP response is $160 \mu \mathrm{V}$ in amplitude, generated by transcranial electric stimulation of 3 pulses, 2 ms ISI and $300 \mathrm{~V}(\mathrm{~A})$. During stimulation, the anode was at $M 3$ the cathode was at Mz. A simultaneous APB and ADQ muscle response is also shown.

Note the absence of the single pulse responses (B) and the facial MEP onset latency of $10 \mathrm{~ms}$ or more, which indicate a central origin. 
(abductor pollicis brevis) 혹은 소지외전근(abductor digiti quinti)을 같이 기록하였고 안면 근육의 단일펄스반응(single pulse response, SPR) (Figure 3)과 $10 \mathrm{~ms}$ 보다 긴 잠복기을 확 인해서 직접적인 말초 안면 근육 자극을 배제하였다[17]. 수술 전과 직후 안면기능은 House-Brackmann grading scheme (HB grade 1 0)을 통해 평가하였다(Table 2)[19].

\section{3. 마취}

Rocuronium bromide $(0.8 \sim 1.0 \mathrm{mg} / \mathrm{kg}$ ) 주입 후 기관 내 튜 브 삽관하고 표적 제어 주입 펌프를 통해 전달 된 프로포폴을 사 용하여 신경 마비를 유지시켰다. 또한 지속적으로 레미펜타닐 을 투여하거나 펜타닐을 투여했다. 마취 유도와 삽관 후에 흡입 제를 사용하지 않았다. 수술 중 마취 수준을 평가하기 위해 bispectral index 방법을 사용하여 뇌파를 모니터링 하였다. 지

Table 2. Facial nerve grading system (HB grade I $\sim \mathrm{VI}$ )

\begin{tabular}{|c|c|c|}
\hline Grade & Description & Characteristics \\
\hline । & Normal & Normal facial function in all areas \\
\hline$\|$ & Mild dysfunction & $\begin{array}{l}\text { Gross: slight weakness noticeable on close inspection; may have very slight synkinesis } \\
\text { At rest: normal symmetry and tone } \\
\text { Motion } \\
\text { Forehead: moderate to good function/eye: complete closure with minimum } \\
\quad \text { effort/mouth: slight asymmetry }\end{array}$ \\
\hline III & Moderate dysfunction & $\begin{array}{l}\text { Gross: obvious but not disfiguring difference between two sides; noticeable but not } \\
\text { severe synkinesis, contracture, and/or hemifacial spasm } \\
\text { At rest: normal symmetry and tone } \\
\text { Motion } \\
\text { Forehead: slight to moderate movement/eye: complete closure with effort/mouth: } \\
\text { slightly weak with maximum effort }\end{array}$ \\
\hline IV & Moderately severe dysfunction & $\begin{array}{l}\text { Gross: obvious weakness and/or disfiguring asymmetry } \\
\text { At rest: normal symmetry and tone } \\
\text { Motion } \\
\text { Forehead: none/eye: incomplete closure/mouth: asymmetric with maximum effort }\end{array}$ \\
\hline V & Severe dysfunction & $\begin{array}{l}\text { Gross: only barely perceptible motion } \\
\text { At rest: asymmetry } \\
\text { Motion } \\
\quad \text { Forehead: none/eye: incomplete closure/mouth: slight movement }\end{array}$ \\
\hline $\mathrm{VI}$ & Total paralysis & No movement \\
\hline
\end{tabular}

Abbreviation: HB, House-Brackmann.

Table 3. Correlation between neurophysiological data and postoperative facial nerve outcomes

\begin{tabular}{|c|c|c|c|c|c|c|c|c|}
\hline No. & Sex & Age & Diagnosis & $\begin{array}{l}\text { Size } \\
(\mathrm{cm})\end{array}$ & $\begin{array}{l}\text { Stimulation } \\
\text { Intensity }\end{array}$ & $\begin{array}{l}\text { Final facial MEP } \\
\text { amplitude (\%) }\end{array}$ & $\begin{array}{l}\text { Pre-operative } \\
\text { HB grade }\end{array}$ & $\begin{array}{c}\text { Post-operative } \\
\text { HB grade }\end{array}$ \\
\hline 1 & $\mathrm{~F}$ & 43 & LT VS & 3.3 & $300 \mathrm{~V}$ & $100 \%(100 \mu \mathrm{V})$ & 1 & 1 \\
\hline 2 & $\mathrm{~F}$ & 62 & LT VS & 3.1 & $220 \mathrm{~V} \rightarrow 300 \mathrm{~V}$ & $120 \%(250 \rightarrow 300 \mu \mathrm{V})$ & 1 & 2 \\
\hline 3 & $\mathrm{~F}$ & 58 & LT CPA MNG & 4.7 & $200 \mathrm{~V}$ & $100 \%(220 \mu \mathrm{V})$ & 1 & 1 \\
\hline 4 & $\mathrm{~F}$ & 64 & RT VS & 3.1 & $500 \mathrm{~V}$ & $100 \%(200 \mu \mathrm{V})$ & 1 & 1 \\
\hline 5 & M & 39 & RT VS & 2 & $200 \mathrm{~V}$ & $160 \%(50 \rightarrow 80 \mu \mathrm{V})$ & 1 & 1 \\
\hline 6 & $\mathrm{~F}$ & 35 & RT VS & 4 & $250 \mathrm{~V}$ & $100 \%(400 \mu \mathrm{V})$ & 1 & 2 \\
\hline 7 & M & 47 & LT VS & 3.5 & $300 \mathrm{~V}$ & $100 \%(300 \mu \mathrm{V})$ & 1 & 1 \\
\hline 8 & $\mathrm{~F}$ & 58 & HEMANGIO-BLASTOMA & 2.6 & $400 \mathrm{~V}$ & $100 \%(160 \mu \mathrm{V})$ & 1 & 1 \\
\hline 9 & $\mathrm{~F}$ & 57 & RT CPA MNG & 2.7 & $300 \mathrm{~V}$ & $100 \%(150 \mu \mathrm{V})$ & 1 & 1 \\
\hline 10 & $\mathrm{~F}$ & 56 & LT CPA MNG & 3.1 & $400 \mathrm{~V} \rightarrow 630 \mathrm{~V}$ & $50 \%(30 \rightarrow 15 \mu \mathrm{V})$ & 1 & 3 \\
\hline 11 & M & 23 & LT VS(NF2) & 3.6 & $300 \mathrm{~V} \rightarrow 350 \mathrm{~V}$ & $100 \%(150 \mu \mathrm{V})$ & 1 & 2 \\
\hline 12 & $\mathrm{~F}$ & 61 & LT VS & 2.9 & $300 \mathrm{~V}$ & $100 \%(200 \mu \mathrm{V})$ & 1 & 2 \\
\hline 13 & $M$ & 46 & RT VS & 3.6 & $300 \mathrm{~V}$ & $100 \%(60 \mu \mathrm{V})$ & 1 & 1 \\
\hline 14 & M & 59 & $\begin{array}{l}\text { RT JUGULAR FORAMEN } \\
\text { SCHWANNOMA }\end{array}$ & 3.9 & $300 \mathrm{~V}$ & $160 \%(50 \rightarrow 80 \mu \mathrm{V})$ & 1 & 1 \\
\hline
\end{tabular}

Abbreviations: FMEP, facial motor evoked potential; HB, House-Brackmann; VS, vestibular schwannoma; NF2, neurofibromatosis type 2; CPA, cerebellopontine angle; MNG, meningioma. 
수는 40 60의 범위로 유지하였다. 정중신경을 4번 연속적으 로 자극한 후 엄지손가락의 움직임을 관찰하는 사연속자극 (train of four, TOF)검사가 적어도 2번 이상 되도록 근이완제 (neuromuscular blocking agent)의 양을 적절하게 유지했다.

\section{4. 통계학적 분석}

SPSS version 1.0.0 (SPSS Inc., Chicago, IL, USA)을 이용하 여 수행되었다. BASELINE TO FINAL 안면운동유발전위 진폭 비의 $50 \%$ 이상 감소여부와 수술 직후 안면 신경 $\mathrm{HB}$ grade 간의 유의성을 카이 제곱 검정(chi-squared test)을 통해 분석하였 다. 수술 직후 $\mathrm{HB}$ grade 1 2을 만족스러운 결과, $\mathrm{HB}$ grade 3 6 을 불만족스러운 결과로 평가하였다[18]. $P<0.05$ 일 경우 통 계학적으로 유의하다고 하였다.

\section{결 과}

다중펄스경두개전기자극을 이용한 안면운동유발전위를 실 행한 모든 환자(14/14)에게서 수술 중에 안면 신경의 기능적인 완전성을 감시했다(Table 3). 안면 근육에서 단일펄스반응의
부재와 $10 \mathrm{~ms}$ 이상의 잠복기를 확인해서 직접적인 말초안면근 육의 자극을 방지하였다(Figure 3). 평균 자극 세기는 330.71 $( \pm 114.58) \mathrm{V}$ 이고, 환자의 안면운동유발전위의 평균 잠복기는 $13.5( \pm 1.5) \mathrm{ms}$ 이고, 평균 진폭은 $166.42( \pm 98.24) \mu \mathrm{V}$ 이였 다. 수술 중 1명의 환자에서 안면운동유발전위 진폭비가 $50 \%$ 이상 감소되었고 수술 후 환자에게 불만족스러운 안면 신경 $\mathrm{HB}$ grade 3 가 되었다. 13 명의 환자에서는 잠복기와 진폭의 유의한 변화없이 종료되었고 수술 후 만족스러운 안면 신경 $\mathrm{HB}$ grade 1 2이였다. 진폭비의 $50 \%$ 감소여부와 안면 신경 $\mathrm{HB}$ grade을 교차분석하여 $\chi^{2}=14.000, P<0.001$ 으로 유의성을 확인하였 다(Table 4). 이 중에서 수술 종료 전 진폭이 $120 \%$ 증가되었고 HB grade 2 인 환자 1 명, $100 \%$ 유지되었고 HB grade 2 인 환자 3 명 이였다. 즉, 안면운동유발전위는 호전되거나 유지되었지만 $\mathrm{HB}$ grade는 가벼운 악화를 나타낸 것이다. 미세한 진폭의 증가 는 수술 종료 전 환자를 깨우기 위해 마취의 심도가 낮아져서 마 취가 깊었던 기준파형 때보다 진폭이 커질 수 있다. 진폭의 변화 는 없었지만 HB grade의 가벼운 악화는 두 개외 전기 자극의 전 파를 방지하기 위해 최대상자극을 줄 수 없고 비교적 약한 자극 을 주기 때문에 전체가 아닌 부분적인 안면 신경의 흥분을 나타

Table 4. Correlation between a reduction in amplitude of more than 50\% of FMEP and postoperative facial nerve outcomes

\begin{tabular}{|c|c|c|c|c|}
\hline & & \multicolumn{2}{|c|}{ Postoperative facial nerve HB GRAGE } & \multirow{2}{*}{$\chi^{2}$} \\
\hline & & HB grage $2 \geq$ & HB grade $2<$ & \\
\hline Baseline to final Amplitude & $\begin{array}{l}50 \%< \\
50 \% \geq\end{array}$ & $\begin{array}{c}13(100.0) \\
0(0.0)\end{array}$ & $\begin{array}{c}0(0.0) \\
1(100.0)\end{array}$ & $14.00^{\star \star \star}$ \\
\hline Total & & $13(92.9)$ & $1(7.1)$ & $P=0.000$ \\
\hline
\end{tabular}

Chi-squared test, ${ }^{\star} P<0.05 ;{ }^{*} P<0.01 ; * \star \star P<0.001$.
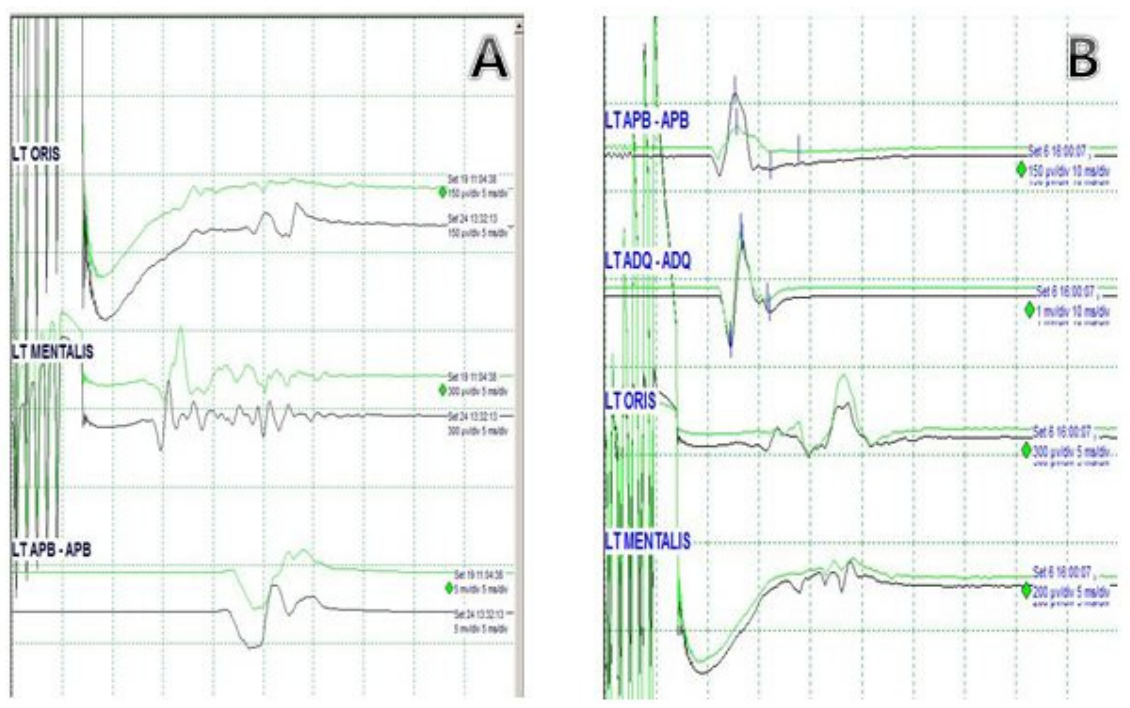

Figure 4. An example of facial MEP recorded from the left orbicularis oris (o. oris) and mentalis. In the left picture (A), The facial MEP response is $300 \mu \mathrm{V}$ in amplitude, generated by transcranial electric stimulation of 5 pulses, 2 ms ISI and 300 V (A). During stimulation, the anode was at M4 and the cathode was at Mz. On the mentalis rather than orbicularis oris, a smaller stimulus artifact and a larger CMAP occurs (A). Whereas in the right picture (B), a smaller artifact and a larger CMAP occurs on the orbicularis oris rather than mentalis. FMEP Recorded the o.oris and mentalis together can improve the accuracy and success rate rather than FMEP recorded from only the o.oris. 
낼 수 있기에 미세한 안면 신경의 손상은 안면운동유발전위 진 폭의 변화가 없을 수도 있기 때문이다[18]. 그래서 진폭의 변화 가 없으면 상관없으나 감소되거나 소실되면 직접적인 안면 신 경 전기자극법을 이용해서 안면 신경의 추가적인 기능 확인이 필요하다.

\section{고 찰}

다중펄스경두개전기자극을 이용한 안면운동유발전위는 자 유 진행 근전도와 직접적인 안면 신경 자극법의 한계점을 보완 해서 소뇌교각 종양수술에서 수술진행에 방해없이 실시간으로 수술초기 피부절개부터 수술 끝 피부봉합 완료시까지 안면 신 경의 기능적 완전성을 감시할 수 있다.

그러나 자극의 과도한 전파로 인해 피질연수로뿐만 아니라 두개 외로 직접적인 말초 안면 근육 자극이 생겨서 안면 신경에 손상이 생겨도 안면운동유발전위는 변화가 없어 위음성이 될 수 있다. 그래서 안면 근육의 단일펄스반응의 부재와 $10 \mathrm{~ms}$ 이 상의 잠복기를 확인하여 자극 세기를 조절하고 말초 안면 근육 이 직접적으로 흥분되는 것을 방지하였다. 또한 low frequency filter 를 100 150 HZ 까지 조절해서 자극 잡파를 최소화시켜 자극파형과 안면 근육 반응이 혼합되지 않도록 하였다. M3-M4 자극법보다 $\mathrm{Mz}-\mathrm{M} 3 / \mathrm{M} 4$ 자극법은 자극으로 인한 환자의 움직 임도 거의 없고 검사의 정확도도 좋아진다[20]. 본 연구에서는 구륜근과 턱근를 동시에 감시해서 구륜근만을 검사할 때보다 검사 정확도와 성공률을 높였다(Figure 4).

Baseline to final 안면운동유발전위 진폭비가 $50 \%$ 이상 감 소될 때를 경고기준으로 하여 수술 직후 안면 신경의 HB grade 가 만족스러운 grade 1 2와 불만족스러운 grade 3 6에서 유 의하였다. 그래서 집도의는 소뇌교각 종양 수술 중에 안면운동 유발전위를 통해 안면 신경의 기능적인 완전성을 예측하는데 도움이 될 수 있다.

결론적으로, 소뇌교각 종양 수술 중에 자유 진행 근전도와 직 접적인 안면 신경 자극법을 이용해서 안면 신경의 위치를 파악 하고 안면운동유발전위로 기능적인 완전성을 확인하면서 종양 절제를 해서 중대한 후유증인 안면 마비 발생률를 최소화할 수 있다.

\section{요 약}

다중펄스경두개전기자극(mpTES)을 이용한 안면운동유발 전위(FMEP)는 자유 진행 근전도와 직접적인 안면 신경 자극법
의 한계점을 보완하고 소뇌교각 종양 수술 중에 안면 신경의 기 능적인 완전성을 예측할 수 있다. 본 논문의 목적은 이 검사의 표 준화된 검사방법과 안면 신경의 기능예측인자로서의 유용성을 알아보고 수술 후 중대한 후유증인 안면마비 발생률을 최소화 하는 것이다. $\mathrm{Mz}$ (음극)-M3, M4 (양극) 전극으로 경두개전기자 극을 주고 안면운동유발전위의 단일펄스반응 $(\mathrm{SPR})$ 의 부재와 $10 \mathrm{~ms}$ 이상의 잠복기를 확인해서 직접적인 두개 외 말초 안면 근 육 자극을 배제하고 구륜근(orbicularis oris)과 턱근(mentalis) 에서 동시에 측정하면 구륜근에서만 측정했을 때보다 안면운동 유발전위의 정확도와 성공률을 높일 수 있다. 본 논문에서는 안 면운동유발전위의 $50 \%$ 진폭감소를 경고기준으로 해서 수술 직 후 안면 신경의 결과를 효과적으로 예측할 수 있었다. 결론적으 로, 소뇌교각 종양 수술 중에 $\mathrm{FMEP}$ 는 자유 진행 근전도와 직접 적인 안면 신경 자극법과 더불어서 수술 후 중대한 후유증인 안 면 마비 발생률을 최소화 할 수 있는 유용한 검사방법이다.

\section{Acknowledgements: None \\ Conflict of interest: None}

Author's information (Position): Baek JS ${ }^{1}$, M.T.; Park SK ${ }^{1}$, M.T.: Kim DJ ${ }^{1}$, M.T.; Park CW ${ }^{1}$, M.T.; Lim $\mathrm{SH}^{1}$, M.T.; Lee $\mathrm{JH}^{2}$, Professor; Cho $\mathrm{YK}^{3}$, Professor.

\section{REFERENCES}

1. Sala F, Manganotti P, Tramontano V, Bricolo A, Gerosa M. Monitoring of motor pathways during brain stem surgery: what we have achieved and what we still miss? Neurophysiol Clin. 2007;37:399-406.

2. Goldbrunner RH, Schlake HP, Milewski C, Tonn JC, Helms J, Roosen K. Quantitative parameters of intraoperative electromyography predict facial nerve outcomes for vestibular schwannoma surgery. Neurosurgery. 2000;46:1140-1146.

3. Harper CM, Daube JR. Facial nerve electromyography and other cranial nerve monitoring. J Clin Neurophysiol. 1998;15: 206-216.

4. Moller AR, Jannetta PJ. Preservation of facial function during removal of acoustic neuromas: use of monopolar constant-voltage stimulation and EMG. J Neurosurg. 1984;61: 757-760.

5. Romstock J, Strauss C, Fahlbusch R. Continuous electromyography monitoring of motor cranial nerves during cerebellopontine angle surgery. J Neurosurg. 2000;93:586-593.

6. Hone SW, Commins DJ, Rames P, Chen JM, Rowed D, McLean A, et al. Prognostic factors in intraoperative facial nerve monitoring for acoustic neuroma. J Otolaryngol. 1997; 26:374-378.

7. Nakao Y, Piccirillo E, Falcioni M, Taibah A, Kobayashi T, Sanna M. Electromyographic evaluation of facial nerve damage in acoustic neuroma surgery. Otol Neurotol. 2001;22:554-557. 
8. Silverman H, Willcox TO, Rosenberg SI, Seidman MD. Prediction of facial nerve function following acoustic neuroma resection using intraoperative facial nerve stimulation. Laryngoscope. 1994;104:539-544.

9. Sobottka SB, Schackert G, May SA, Wiegleb M, Reiss G. Intraoperative facial nerve monitoring (IFNM) predicts facial nerve outcome after resection of vestibular schwannoma. Acta Neurochir. 1998;140:235-243.

10. Yingling $\mathrm{CD}$, Gardi JN. Intraoperative monitoring of facial and cochlear nerves during acoustic neuroma surgery. 1992. Neurosurg Clin N Am. 2008;19:289-315.

11. Akagami R, Dong CC, Westerberg BD. Localized transcranial electrical motor evoked potentials for monitoring cranial nerves in cranial base surgery. Neurosurgery. 2005;57:78-85.

12. Fukuda M, Oishi M, Takao T, Saito A, Fujii Y. Facial nerve motor evoked potential monitoring during skull base surgery predicts facial nerve outcome. J Neurol Neurosurg Psychiatry. 2008;79: 1066-1070.

13. Samii M, Matthies C. Management of 1000 vestibular schwannomas (acoustic neuromas): the facial nerve-preservation and restitution of function. Neurosurgery. 1997;40:684-694.

14. Calancie B, Harris W, Broton JG, Alexeeva N, Green BA. "Threshold-level" multipulse transcranial electrical stimulation of motor cortex for intraoperative monitoring of spinal motor tracts: description of method and comparison to somatosensory evoked potential monitoring. J Neurosurg. 1998;88: 457-470.

15. Dong CC, MacDonald DB, Janusz MT. Intraoperative spinal cord monitoring during descending thoracic and thoracoabdominal aneurysm surgery. Ann Thorac Surg. 2002; 74:1873-1876.

16. Jacobs MJ, Meylaerts SA, de Haan P, de Mol BA, Kalkman CJ. Strategies to prevent neurologic deficit based on motor-evoked potentials in type I and II thoracoabdominal aortic aneurysm repair. J Vasc Surg. 1999;29:48-57.

17. Ulkatan S, Deletis V, Fernandez-Conejero I. Central or peripheral activations of the facial nerve? J Neurosurg. 2007;106: 519-520.

18. Dong CC, MacDonald DB, Akagami R, Westerberg B, Alkhani A, Kanaan I, et al. Intraoperative facial motor evoked potential monitoring with transcranial electrical stimulation during skull base surgery. Clin Neurophysiol. 2005;116:588-596.

19. House JW, Brackmann DE. Facial nerve grading system. Otolaryngol Head Neck Surg. 1985;93:146-147.

20. Park SK. Intraoperative neurophysiological monitoring in cerebello pontine angle tumor. Korean J Clin Lab Sci. 2014;46: $38-45$. 